\title{
Experimental investigation on turbidity current venting under restrained outflow discharges
}

\author{
S. Chamoun, G. De Cesare \& A.J. Schleiss \\ Laboratory of Hydraulic Constructions ( LCH), Ecole Polytechnique Fédérale de Lausanne (EPFL), Lausanne, \\ Switzerland
}

\begin{abstract}
Reservoir sedimentation is a worldwide problem affecting sustainable storage use as well as sediment transport downstream of dams. Various techniques are applied for sediment mitigation, among which, venting of turbidity currents. This paper reviews, discusses and evaluates venting of turbidity currents based on an experimental approach. Data acquisition during the tests is accomplished using five different measuring instruments. The efficiency of venting is analyzed by varying the relative outflow discharge. The study reveals the potential of optimizing venting operations in terms of water losses by employing adequate outlet discharges during venting.
\end{abstract}

\section{INTRODUCTION}

Sedimentation is a growing issue in most reservoirs worldwide. Annual losses occur in reservoirs, owing to the fact that the annual volume decrease in reservoir capacity due to sedimentation is higher than the global increase in storage capacity due to the construction of new reservoirs (Oehy \& Schleiss 2007). This storage capacity will decrease by more than $50 \%$ in 2100 without considering the construction of new dams (Sumi \& Hirose 2009). Besides reducing the storage capacity of a reservoir by filling it with sediments, sediment starvation in the downstream environment may also occur (Kondolf 1997). For these reasons, many sediment management techniques exist (Basson \& Rooseboom 1999, De Cesare \& Lafitte 2007) and aim to balance sediment inflow and outflow in a reservoir and to preserve its capacity. The main sediment evacuation techniques are illustrated in Figure 1 below.

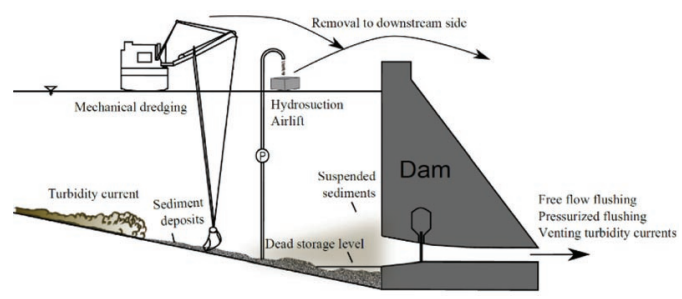

Figure 1. Commonly used sediment evacuation techniques.
One of the main transportation processes of suspended sediments in long and deep reservoirs is through turbidity currents. The latter are formed during yearly floods when sediment-laden flows arriving from the watershed reach a reservoir and plunge beneath the clear water surface due to their high density. After plunging, a turbidity current is formed and flows on the bed of the reservoir, entraining the suspended sediments near the dam. In case no outlets/intakes operate, suspended sediments of the turbidity currents will settle and fill the reservoir on the long-term. Therefore, in reservoirs where turbidity currents frequently occur or present the main source of inflowing sediments, venting represents the most adequate means to evacuate the entrained sediments.

This technique is more and more appreciated by dam operators mainly for economic but also for environmental reasons (Morris \& Fan 1997). In fact, unlike other operations such as flushing or dredging, venting of turbidity currents deals with a direct transiting of the sediments while they reach the dam. Therefore, if applied in optimized conditions, the main advantage of such an operation is that sediments are evacuated before they settle. Additionally, drawdown of the reservoir is not needed, which makes this technique even more appealing particularly in arid regions where water is in shortage (Brandt 2001).

However, venting of turbidity currents in optimized conditions can be complex. In fact, a successful venting operation is directly linked to a good knowledge of the dynamics of the turbidity currents reaching the dam. Since such currents occur in flood conditions, field measurements are 
not always possible and available. Many researchers emphasized the importance of investigating venting of turbidity currents (Ren \& Ning 1985, Morris \& Fan 1997, Batuca \& Jordaan 2000) but very few (e.g. Yu et al. 2004, Fan 2008, Wan et al. 2010, Lee et al. 2014) did quantitative research on the subject. Thus, a lack of research and knowledge exist in the field of turbidity currents venting. For this reason, the investigation of venting operations is crucial to improve its efficiency.

In the present paper, venting of turbidity currents is studied based on an experimental approach. A global overview of venting applications is firstly presented, then important parameters affecting the efficiency of venting are introduced. Finally, the effect of restrained outflow discharges on venting efficiencies is analyzed.

\section{GLOBAL PREVIEW OF THE APPLICATION OF VENTING TURBIDITY CURRENTS}

\subsection{Venting worldwide}

Venting is applied in reservoirs where the major part of sediments is entrained by turbidity currents. Basson \& Rooseboom (1997) proposed a scheme for preferred reservoir operations depending on two parameters taking into account the reservoir's capacity, the mean sediment yield and the mean annual runoff.

Many reservoirs worldwide use venting operations as their main sediment evacuation technique. A few examples include the Elephant Butte Reservoir (USA), the Xiolangdi Reservoir (China), the Mapragg and Gigerwald Reservoirs (Switzerland), the Dez Dam Reservoir (Iran), and the Nebeur Reservoir (Tunisia).

Venting efficiencies globally range from $0.9 \%$ to $100 \%$. This large variability is due to different hydrological, operational, and topographical conditions. Even the same reservoir can have high variations of venting efficiencies from one flood event to another. For instance, in the Sefid Rud reservoir, venting was first applied while turbidity currents did not reach the lower limit of the outlet. The efficiency drastically increased once this gap was filled with deposited sediments and turbidity currents started flowing directly at the level of the outlets (Morris \& Fan 1997). As a result, it is of great importance to assess the parameters which play a major role in the efficiency of a venting operation and to investigate the effect of each of these parameters.

\subsection{Venting efficiency}

Practically, the efficiency of venting can be evaluated by comparing the mass of sediments evacuated through a venting operation to the mass of sediments entrained by a turbidity current into the reservoir during a flood event (Morris \& Fan 1997, Lee et al. 2014):

$$
V E=\frac{m_{\text {out }}}{m_{\text {in }}}=\frac{\sum_{i=0}^{T}\left(\mathrm{C}_{\text {out }_{i}} Q_{\text {out }_{i}}\right)}{\sum_{i=0}^{T}\left(C_{i n_{i}} Q_{i n_{i}}\right)}
$$

where $m_{\text {out }}$ and $m_{\text {in }}$ represent the masses of outflow and inflow sediments respectively, $C_{\text {out }, i}$ and $C_{\text {in }, i}$ are the respective suspended sediment concentrations of outflow and inflow at time $i, Q_{\text {out }, i}$ and $Q_{i n, i}$ are the respective outflow and inflow discharges at time $i$ and $T$ is the total duration of the turbidity current inflow close to the dam site. However, it is hard to address and compare venting efficiencies with field data from different reservoirs, as the measurements of discharges and concentrations particularly related to the inflow can be located at different stages of the reservoir. For instance, in the Heisonglin Reservoir, inflow is monitored at a hydrologic station located $7.5 \mathrm{~km}$ upstream of the dam while at the Sefid Rud Reservoir, two stations (at Gilvan and Lowshan) monitor at more or less $23 \mathrm{~km}$ (Morris \& Fan 1997). Thus, when comparing outflow to inflow characteristics, one should always take into account the monitoring locations as the inflow varies due to the deposition and erosion sediment fluxes.

\subsection{Parameters affecting venting efficiencies}

Many parameters affect the efficiency of venting turbidity currents. The outflow discharge, venting timing, and outlet elevation are among the most discussed parameters in literature (Morris \& Fan 1997, Yu et al. 2004, Fan 2008, Lee et al. 2014). However, other parameters of morphological and topographical nature such as the watershed's soil type and the slope of the thalweg which can have a direct effect on the characteristics (e.g. concentration and grain size distribution) and dynamics (e.g. subcritical or supercritical) of the turbidity current approaching the dam and thus on the efficiency of its evacuation. Also, the intensity and duration of the flood event affect the inflow duration of the turbidity current and consequently the duration of venting. Finally, legal, economic and downstream environmental aspects impact decisions concerning venting of turbidity currents (Palmieri et al. 2001, Schneider et al. 2007).

In this paper, the outflow discharge is experimentally investigated. 


\section{EXPERIMENTAL SET-UP AND INSTRUMENTATION}

\subsection{Set-up description}

Experimental tests are carried out in an $8.55 \mathrm{~m}$ long, $0.27 \mathrm{~m}$ wide, and $1 \mathrm{~m}$ depth flume that can be tilted with a slope ranging from 0 to $5 \%$. The slope investigated in the present work is horizontal $(0 \%)$.

The flume is divided into three parts: an upstream compartment, also called the head tank $\left(0.8 \times 0.27 \times 1 \mathrm{~m}^{3}\right)$, the main flume $\left(6.7 \times 0.27 \times 1 \mathrm{~m}^{3}\right)$, and a downstream compartment $\left(1.05 \times 0.27 \times 1 \mathrm{~m}^{3}\right)$.

The head tank receives the water-sediment mixture from the mixing tank (number 1 in Fig. 2) situated below the flume. A sliding gate separates the head tank and the main flume (number 2 in Fig. 2). The inlet leading to the main flume consists of an opening of $4.5 \mathrm{~cm}$ where a tranquilizer is placed. Its role is to regulate the scale of turbulence of the released current and to give a uniform distribution for the velocity field of the current.

The main flume simulates the reservoir where the turbidity current flows before being vented. At the end of the main flume (6.7 $\mathrm{m}$ from the inlet), a wall simulating the dam is located and an outlet is placed at its bottom (number 4 in Fig. 2). This wall separates the main flume from the downstream compartment (number 3 in Fig. 2) and also serves as a weir to keep the water level constant in the main flume during the tests. The downstream compartment serves as a container receiving the residual water.

Note that the mixing tank is equipped with a submerged pump that allows the recirculation of the mixture and thus continuous suspension of the material and stable concentrations. Additionally, the head tank has a propeller mixer that allows mixing throughout the test to avoid deposition and thus a decrease of inflow concentrations during the tests.

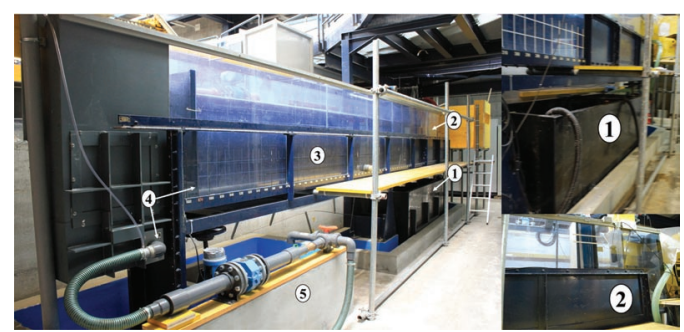

Figure 2. View of the experimental installation. The mixing tank (1) is shown below the flume (2), the downstream compartment of the flume (3) is also shown along with the bottom outlet (4) and the downstream basin (5).
The bottom outlet, centered over the width, has a width of $9 \mathrm{~cm}$ and a height of $12 \mathrm{~cm}$. It is linked to a downstream basin (number 5 in Fig. 2) through a $50 \mathrm{~mm}$ pipe where a valve and an electromagnetic flowmeter are placed in order to control outflow discharges. After venting the current, the latter reaches the downstream basin where continuous measurements of the concentration are made using a turbidity probe. Finally, the collected sediments are pumped again into the mixing tank and reused for a new test.

\subsection{Instrumentation}

During the tests, concentrations, water levels, velocities, deposition thicknesses, as well as discharges, are measured continuously. In Figure 3 below, the instruments described in this section are schematically positioned on the experimental installation. The annotation in the figure corresponds to the numbers used in the following description of the instruments.

1. Electromagnetic flowmeter: a flowmeter is placed at the upstream side between the mixing tank and the head tank to monitor inflowing discharges of the turbidity current $Q_{i n}$. A second one is placed downstream of the main flume to regulate the outflow discharge $Q_{\text {out }}$.

2. Ultrasonic level probes: used for the monitoring of water levels in the head tank and the main flume. It is important that the water levels are kept constant and equal in order to avoid fluxes between the clear water in the flume and the mixture in the head tank. This would affect the mixture's concentration as well as the inflowing discharges.

3. Turbidity probes: a turbidity probe is placed in the head tank and measures inflowing concentrations $C_{i n}$. A second turbidity probe is placed in the downstream basin and measures outflowing concentrations $C_{\text {out }}$ of the water-sediment mixture. Note that measurements of $C_{\text {out }}$ is done in a small container located at the exit of the outflow pipe, before the water overflows to the main downstream basin.

4. Depositometer: This instrument was developed by De Rooij et al. (1999) and measures the

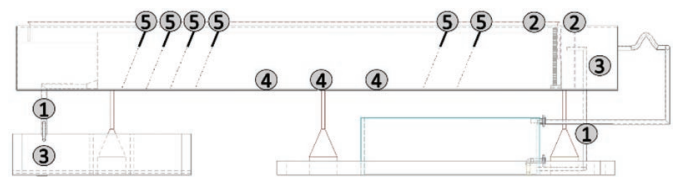

Figure 3. Position of measuring instruments on the experimental structure. 
sediment deposit thickness at the bottom of the flume. It is based on the relationship between the thickness of a deposit and its electrical resistance. It consists of a reference electrode (stainless steel rod) placed along the flume at a height of $50 \mathrm{~cm}$ from the bottom and 62 bottom electrodes (diameter $\mathrm{d}=6 \mathrm{~mm}$ ) implemented inside the bed of the flume. Thus, 62 measurements of thicknesses are recorded along the flume throughout the test.

5. UVP (Ultrasonic Velocity Profilers): Six UVP probes (Takeda 1995) are mounted at $2.8 \mathrm{~m}$, $4.1 \mathrm{~m}, 5.5 \mathrm{~m}, 5.8 \mathrm{~m}, 6.0 \mathrm{~m}$, and $6.2 \mathrm{~m}$ from the inlet respectively. This technique is used to measure velocity profiles of the turbidity current instantaneously and thus gives a continuous monitoring of the flow throughout the tests. The "sampling period" of the UVP is of $38 \mathrm{~ms}$.

6. Thermometer: Temperatures are measured upstream and downstream the main flume for two main reasons: (1) To make sure temperatures between clear water of the main flume and the mixture in the head tank are more or less the same so that density differences are only imposed by the presence of suspended sediments and (2) because the resistance measured by the depositometer also depends on the temperature of water and thus should be taken into account.

Acquisition frequency for instruments 1 to 4 is around $2.75 \mathrm{~Hz}$, which means that data was recorded each $0.36 \mathrm{~s}$ on average.

\subsection{Sediment material}

A fine polymer powder is mixed with water to create the dense fluid in this study. The fine sediments are a high performance thermoplastic polyurethane (TPU) with characteristic diameter $\mathrm{d}_{10}=66.5 \mu \mathrm{m}$, $\mathrm{d}_{50}=140 \mu \mathrm{m}$ and $\mathrm{d}_{90}=214 \mu \mathrm{m}$ where $\mathrm{d}_{\mathrm{x}}$ represents the grain size diameter for which $\mathrm{x} \%$ of the amount of sediments has smaller diameters. The density of the sediment material is $1160 \mathrm{~kg} / \mathrm{m}^{3}$. Figure 4 shows the grain size distribution of the sediment material.

Note that the geometrical dimensions of the experimental model are not based on a specific similitude scale with reality. It is used to assess a general venting behavior under controlled conditions and is not a case study for a specific prototype reservoir. Nevertheless, the physical process for the specific set-up could be scaled up for example on a prototype bottom outlet without significant scale effects. The latter are strongly reduced using sediment material which has a lower density than prototype sediments in order for the current to be able to keep the sediments suspended with

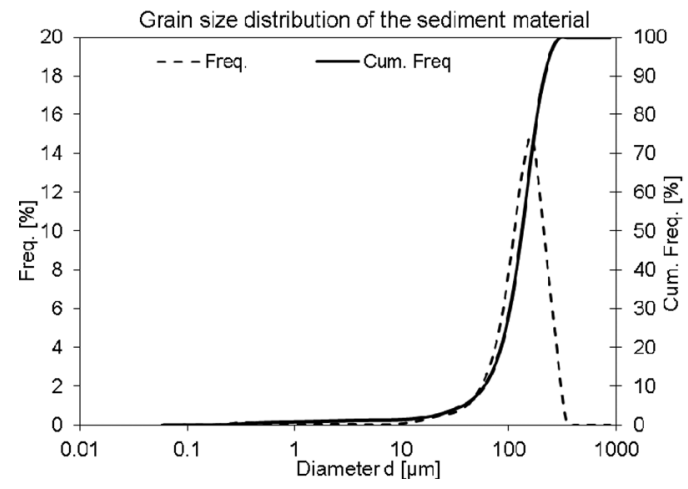

Figure 4. Grain size distribution of the sediments.

lower discharges than what is typically found on the field. For instance, the buoyancy fluxes could be estimated and compared with similar studies (e.g. Altinakar et al. 1990; Garcia \& Parker 1993; Oehy \& Schleiss 2007).

\section{EXPERIMENTAL PROCEDURE}

At the beginning of each test, the mixing tank is filled with water and a specific mass of the fine powdery material is added until the desired concentration is obtained. Meanwhile, the main channel where the current will develop is filled with clear water up to a level of $80 \mathrm{~cm}$.

Once the mixture ready, it is pumped to the head tank, and returns to the mixing tank through a recirculation pipe. This recirculation lasts for a few minutes and helps in the regulation of the flow rate through the electromagnetic flowmeter, ensuring good mixing and homogeneous concentrations between the two reservoirs.

Before starting the test, the water level in the head tank and the main channel are equal in order to prevent a burst-like initial inflow when opening the gate to release the turbidity current. The concentration of the mixture is continuously measured using the turbidity probe placed in the head tank.

Once the concentration measured reaches the desired value, the recirculation is stopped, the sliding gate separating the head tank and the main flume is opened and the turbidity current is released through the inlet into the main flume. The turbidity current then flows along the channel through a distance of $6.70 \mathrm{~m}$ and is monitored for the whole duration of the test. When it reaches the bottom outlet, the latter is opened with a specific discharge.

The vented current reaches the downstream basin where continuous concentration measurements 
are achieved using the turbidity probe as described in section 3.2. Venting efficiencies are then calculated for different scenarios.

\section{RESULTS}

\subsection{Turbidity currents inflow characteristics}

The turbidity currents simulated in this work should have very similar inflow properties in order to avoid the effect of the dynamics of the current on its venting. Therefore, the stability of inflowing concentrations and discharges as well as water levels upstream and downstream of the main flume were checked:

- Average inflow concentrations of the considered tests are of $27 \mathrm{~g} / \mathrm{l}$. The average standard deviation of this concentration for a single test is of $2.3 \mathrm{~g} / \mathrm{l}$ and the standard deviation of the concentration between different tests is $2.1 \mathrm{~g} / \mathrm{l}$. This means that inflow concentrations were sufficiently constant throughout the tests.

- Average inflow discharges of the turbidity currents for the considered tests are of $11 / \mathrm{s}$. The average standard deviation of this discharge for a single test is of $5 \times 10^{-3} \mathrm{l} / \mathrm{s}$ and the standard deviation from one test to another is $0.02 \mathrm{l} / \mathrm{s}$. Thus, quasi-steady conditions were ensured at the inlet in terms of concentrations and discharges.

- Water level differences measured between upstream and downstream of the main flume are only $0.4 \mathrm{~cm}$ on average.

In Figure 5, an example of a turbidity current approaching the wall with the outlet is given.

\subsection{Outflow concentration}

Seven tests are considered in this analysis with different outflowing discharges: $Q_{\text {out }} / Q_{\text {in }}=30 \% ; 50 \%$; $65 \% ; 80 \% ; 100 \% ; 115 \% ; 125 \%$. The results show

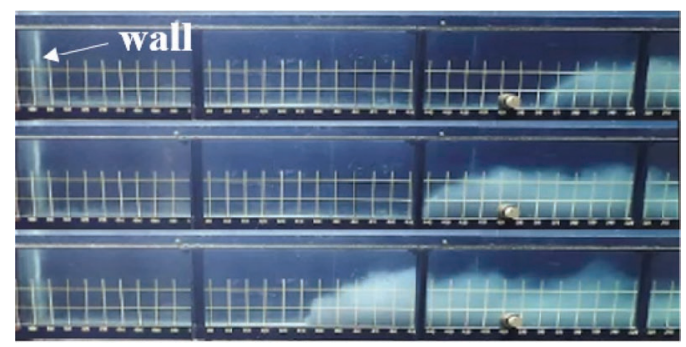

Figure 5. A turbidity current at three different positions $\left(\Delta \mathrm{x}=60 \mathrm{~cm}\right.$, grid size: $\left.10 \times 10 \mathrm{~cm}^{2}\right)$ advancing inside the flume towards the outlet in the wall where it will be vented.

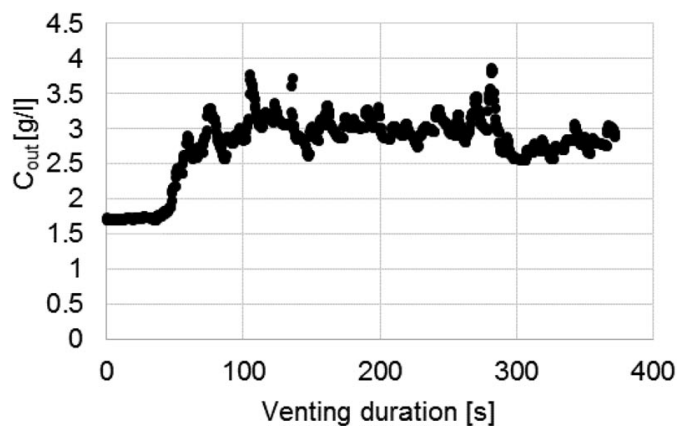

Figure 6. Outflow concentration for $\mathrm{Q}_{\text {out }} / \mathrm{Q}_{\text {in }}=30 \%$ relatively to the duration of venting.

that outflowing concentrations for all the tests have a general common behavior (Fig. 6). Outflow concentrations start by increasing, before reaching a more or less constant value.

The increasing part indicates the venting of the head of the current and the formation of the muddy lake at the vicinity of the outlet. While the plateau shows that steady conditions are reached next to the outlet due to the arrival of the steady body of the current and the fact that the muddy lake formed at the beginning of the venting has partly settled and partly been reflected upstream. This trend was qualitatively predicted by $\mathrm{Yu}$ et al. (2004). Values of the concentrations in this constant zone give a close idea of the concentrations in the steady body of the current reaching the outlet.

The fact that a steady state of the venting is reached means that venting can be optimized based on the discharge of the approaching current when venting with outflow discharges restrained by the inflow discharges.

\subsection{Venting efficiency}

As shown in sections 5.1 and 5.2, at some point of venting, inflowing and outflowing conditions tend to become stable. Therefore, in order to have a representative value of the efficiency of venting for the different outflow conditions, steady conditions should be considered in the calculation. Equation(1) was used to calculate this representative venting efficiency. However, variables were not summed on the whole duration of the test but averaged values of all variables in steady conditions were used to reach an averaged instantaneous venting efficiency. The results for the different $Q_{\text {out }} / Q_{\text {in }}$ are shown in Figure 7.

The increase in venting efficiencies when going from $Q_{\text {out }} / Q_{\text {in }}=0$ to $100 \%$ is more or less linear. However, for values higher than $100 \%$, the 


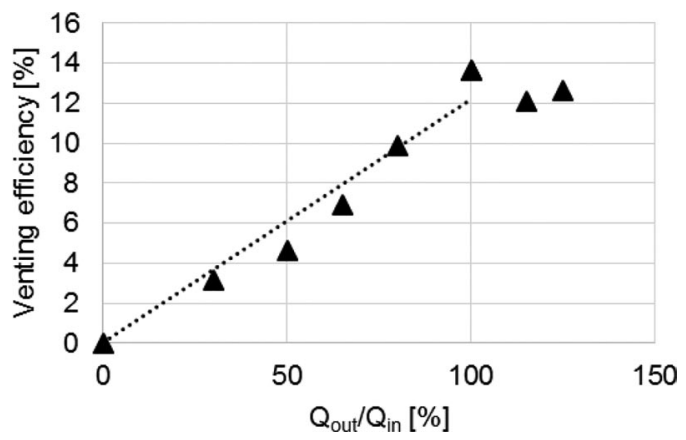

Figure 7. Venting efficiency for different outflow discharges.

efficiency stops increasing and tends to decrease. This is due to the fact that $C_{\text {out }}<C_{\text {in }}$ for the cases where $Q_{\text {out }}>Q_{\text {in }}$.

This suggests the possibility of minimizing water losses during venting operations while keeping high venting efficiencies. In other words, for the case of a flat bottom, venting turbidity currents with $Q_{\text {out }} \gg Q_{\text {in }}$ is not more efficient than venting with $Q_{\text {out }}=Q_{\text {in }}$. Nevertheless, one should keep in mind that the present results are for the case where the timing of the venting is simultaneous with the moment where the turbidity current reaches the dam.

\section{CONCLUSIONS AND FUTURE WORK}

Sedimentation in reservoirs is a growing problem. Turbidity currents are one of the main reasons behind sedimentation in several reservoirs. Therefore, the evacuation of these currents before their settling should be studied and optimized.

Based on extended literature, venting is shown to depend on many parameters such as the timing of the outlet opening, the outlet size and elevation, and the outflow discharge. In the present paper, the effect of outflow discharges restrained to inflow discharges is investigated.

The results reported in this paper show that for the case of a flat bottom and a venting timed with the arrival of the turbidity current to the dam, a maximum venting efficiency can be reached with an outflow discharge that corresponds to the discharge of the turbidity current approaching the dam thus minimizing water losses. Such outcomes are useful for reservoirs regularly facing turbidity currents and provide interesting information for the design of bottom outlets in dam projects. It is also of great interest for reservoirs operating with bottom outlets having restrained capacities.

However, in the present work, deposition measurements for the different tests show that the simulated currents are depositive, which is expected with flat beds. Therefore, in order to have a more representative value of the efficiency, deposition will be taken into account in a second phase of this study.

\section{ACKNOWLEDGEMENTS}

The research reported in the present paper was funded by Swisselectric Research.

\section{REFERENCES}

Altinakar, S., Graf, W.H. \& Hopfinger, E.J., 1990. Weakly depositing turbidity current on a small slope. Journal of Hydraulic Research, 28(1), pp. 55-80.

Basson, G. \& Rooseboom, A., 1997. Dealing with reservoir sedimentation: Prepared for the Water Research Commission, Water Research Commision, South Africa.

Basson, G. \& Rooseboom, A., 1999. Dealing with reservoir sedimentation-Dredging, Water Research Commision, South Africa.

Batuca, D. \& Jordaan, J., 2000. Silting and desilting of reservoirs, Rotterdam: A.A.Balkema.

Brandt, S.A., 2001. A review of reservoir desiltation. International Journal of Sediment Research, 15(3), pp. 321-342.

De Cesare, G. \& Lafitte, R., 2007. Outline of the historical development regarding reservoir sedimentation. In 32nd IAHR Congress, Harmonizing the Demands of Art and Nature in Hydraulics. Venice, Italy.

De Rooij, F., Dalziel, S.B. \& Linden, P.F., 1999. Electrical measurement of sediment layer thickness under suspension flows. Experiments in Fluids, 26(5), pp. $470-474$

Fan, J., 2008. Stratified flow through outlets. Journal of Hydro-environment Research, 2(1), pp. 3-18.

Garcia, M. \& Parker, G., 1993. Experiments on the entrainment of sediment into suspension by a dense bottom current. Journal of Geophysical Research, 98(C3), pp. 4793-4807.

Kondolf, G.M., 1997. Hungry water: Effects of dams and gravel mining on river channels. Environmental Management, 21(4), pp. 533-551.

Lee, F.Z. et al., 2014. Turbid density current venting through reservoir outlets. KSCE Journal of Civil Engineering, 18(2), pp. 694-705.

Morris, G. \& Fan, J., 1997. Reservoir sedimentation handbook: Design and management of dams, reservoirs, and watersheds for sustainable use, McGraw-Hill, New York.

Oehy, C. \& Schleiss, A., 2007. Control of turbidity currents in reservoirs by solid and permeable obstacles. Journal of Hydraulic Engineering 10.1061/ (ASCE)0733-9429(2007)133:6(637). 
Palmieri, A., Shah, F. \& Dinar, A., 2001. Economics of reservoir sedimentation and sustainable management of dams. Journal of environmental management, 61(2), pp. 149-63.

Ren, Z. \& Ning, Q., 1985. Lecture notes of the training course on reservoir sedimentation, Beijing, China: IRTCES.

Schneider, J. et al., 2007. Determination of parameters for venting turbidity currents. In IAHR Congress. Venice, Italy, p. 425.

Sumi, T. \& Hirose, T., 2009. Accumulation of sediment in reservoirs. In Water storage, transport, and distribu- tion. UNESCO-IHE and EOLSS Publishers Co. Ltd., Paris, France, pp. 224-252.

Takeda, Y., 1995. Velocity Profile Measurement by Ultrasonic Doppler Method. Experimental Thermal and Fluid Science, 10(4), pp. 444-453.

Wan, X.Y. et al., 2010. Similarity-based optimal operation of water and sediment in a sediment-laden reservoir. Water Resources Management, 24(15), pp. 4381-4402.

Yu, W.S., Hsu, S.M. \& Fan, K.L., 2004. Experiments on Selective Withdrawal of a Codirectional Two-Layer Flow through a Line Sink. Journal of Hydraulic Engineering, 130(12), pp. 1156-1166. 